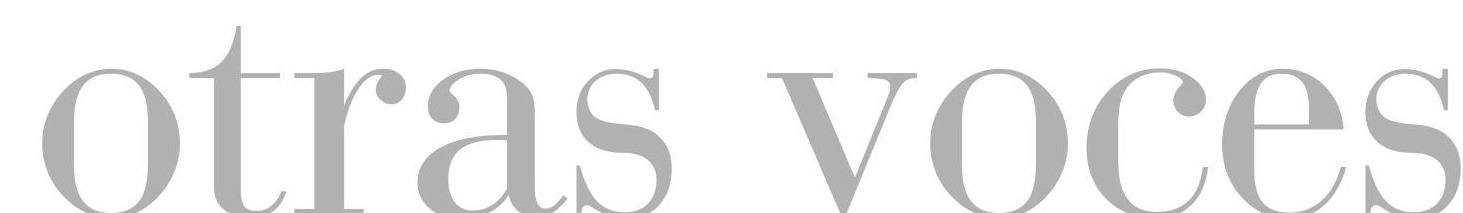





\title{
Traduções e bricolagens: mediações em ocupações de terra no Nordeste de Minas Gerais (Brasil) nas décadas de 1980 e $1990^{1}$
}

\author{
Arnaldo José Zangelmi ${ }^{2}$ \\ Universidade Federal de Ouro Preto, Brasil ${ }^{3}$ \\ arnaldozan@yahoo.com.br \\ Recibido: 25 de noviembre de 2014 \\ Aceptado: 24 de marzo de 2015 \\ Disponible en linea: 30 de noviembre de 2015
}

1 O texto aqui apresentado trata-se de um artigo de reflexão, pois pretende analisar parte dos resultados da pesquisa de doutorado desenvolvida entre 2010 e 2014, sob orientação da prof. Leonilde Medeiros, no Programa de Pós-Graduação de Ciências Sociais em Desenvolvimento, Agricultura e Sociedade, da Universidade Federal Rural do Rio de Janeiro (UFRRJ). Essa pesquisa contou com bolsa de estudos financiada pelo Conselho Nacional de Desenvolvimento Científico e Tecnológico (CNPq/Brasil).

2 Possui graduação em História pela Universidade Federal de Ouro Preto, Mestrado em Extensão Rural pela Universidade Federal de Viçosa e Doutorado em Ciências Sociais pela Universidade Federal Rural do Rio de Janeiro, Brasil.

3 Profesor Adjunto. Área de Ciencias Sociales. Departamento de Historia. 


\section{Traduções e bricolagens: mediações em ocupações de terra no Nordeste de Minas Gerais (Brasil) nas décadas de 1980 e 1990}

\section{Resumo}

O objetivo do trabalho aqui apresentado foi compreender as ações de mediação-desenvolvidas entre militantes de movimentos sociais, trabalhadores rurais e seus adversários- nas ocupações de terra na região Nordeste de Minas Gerais (Brasil) durante as décadas de 1980 e 1990. Foram realizadas entrevistas junto a alguns dos principais atores desse processo, assim como analisado material escrito produzido por várias organizações, como jornais, cartilhas, panfletos, documentos oficiais etc. A atenção está voltada para as articulações entre algumas significações produzidas pelos diversos grupos em relação, para as dinâmicas de construção, desconstrução e reconstrução das relações de representação dos trabalhadores rurais e para as relações entre mobilizações locais e a politica institucional. Destacam-se as relações de aliança e disputa entre os principais grupos que estiveram à frente das ocupações -assim como as fortes reações de seus adversários-interações que influíram decisivamente no desenrolar do processo estudado.

Palavras-chave: mediação; reforma agrária; movimentos sociais

\section{Traducciones y bricolajes: mediaciones en ocupaciones de tierra en el Nordeste de Minas Gerais (Brasil) en las décadas de 1980 y 1990}

\section{Resumen}

El objetivo del trabajo aquí presentado es el de comprender las acciones de mediación -desarrolladas entre militantes de movimientos sociales, trabajadores rurales y sus adversarios- en las ocupaciones de tierra en la región Nordeste de Minas Gerais (Brasil) durante las décadas de 1980 y 1990. Se realizaron entrevistas a algunos de los principales actores de este proceso, así como análisis de material escrito producido por varias organizaciones, tales como periódicos, cartillas, panfletos, documentos oficiales, etc. La atención se centró en las articulaciones entre algunas significaciones producidas por los diversos grupos en relación, en las dinámicas de construcción, deconstrucción y reconstrucción de las relaciones de representación de los trabajadores rurales y en las relaciones entre movilizaciones locales y la politica institucional. Se destacan las relaciones de alianza y disputa entre los principales grupos que estuvieron frente a las ocupaciones - así como las fuertes reacciones de sus adversarios-, interacciones que influyeron decisivamente en el desenvolvimiento del proceso estudiado.

Palabras clave: mediación; reforma agraria; movimientos sociales

\section{Translations and bricolages: mediation in land occupations in the Northeast of Minas Gerais (Brazil) in the 1980s and 1990s}

\section{Summary}

The objective this work is to understand the mediation actions -developed between social movements activists, rural workers and their adversaries- in the land occupations in the Northeast of Minas Gerais (Brazil) during the 1980s and 1990s. Interviews were conducted with some of the major figures in this process, as well as the analysis of written material produced by various organizations such as newspapers, booklets, pamphlets, official documents, etc. It is focused on the joints between some meanings produced by the groups involved, the dynamics of construction, deconstruction and reconstruction of the relations of representation of rural workers as well as on the relations between local mobilization and institutional politics. It highlights the alliance and dispute relations between the major groups that performed the occupations -as well as the strong reactions of his opponents-, interactions that decisively influenced the development of the process studied.

Keywords: mediation; agrarian reform; social movements 
O presente trabalho parte de um esforço de compreensão sobre alguns contornos das mudanças sociais e politicas na atualidade. Os processos de transformação - especialmente aqueles relacionados às buscas organizadas pelo redimensionamento das relações de poder na sociedade- chamam cada vez mais atenção e colocam desafios interessantes para as Ciências Sociais.

Diante desse desafio, o questionamento sobre os efeitos das ações de alguns grupos mobilizados -com suas várias utopias, valores, práticas, relações sociais e políticas- é fundamental para a compreensão dos processos em curso, suas potencialidades, limites e alternativas. Nesse sentido, cresce a necessidade de estudar as ações de grupos comumente denominados como organizações e movimentos sociais, buscando analisar em que medida essas ações acontecem, obtêm adesão, atingem seus objetivos e direcionam os processos sociais, culturais e políticos.

Diante da multiplicidade de fenômenos que envolvem as ações de organizações e movimentos sociais, cabe colocar em questão quais seriam os possíveis elementos que incitariam a mobilização, as ações de enfrentamento e a formação de novos atores políticos. A atenção está aqui direcionada para a noção de mediação (Neves, 2008) enquanto ação especifica fundamental para as mobilizações sociais e políticas. Diante da pergunta 'Por que e como os movimentos sociais acontecem?', questionar as ações de mediação tem apresentado potencial explicativo, pois essas ações podem ter caráter catalisador para a realização das mobilizações sociais.

Nesse sentido, o objetivo da pesquisa aqui apresentada foi compreender as ações de mediação, entendidas em seu caráter múltiplo, processual e relacional-desenvolvidas entre militantes de movimentos sociais, organizações, trabalhadores rurais e seus adversários- direcionadas para a realização de ocupações de terra nos Vales do Jequitinhonha, Mucuri e Rio Doce (Minas Gerais, Brasil), a partir de meados da década de 1980 até meados da década de 1990. 
Essa região, também denominada Nordeste Mineiro, tem um histórico marcante de intensos conflitos pela terra, principalmente a partir da década de 1940. Desde esse período, ocorreu um intenso movimento de sindicalização e construção da reforma agrária como bandeira politica, processo estimulado principalmente pelo Partido Comunista Brasileiro (PCB) e por segmentos progressistas da Igreja Católica. Essas mobilizações crescentes foram obstaculizadas pelo golpe civil-militar de 1964, que deu início a um período ditatorial que, por cerca de vinte anos, limitou consideravelmente as possibilidades de organização da luta pela terra no Brasil. Diante da forte repressão, as lutas se tornaram dispersas e fragmentadas e o movimento sindical fortemente controlado pelo Estado.

Já na década de 1980, como parte do processo de redemocratização do Brasil, houve forte atuação de organizações e movimentos sociais, que redimensionaram as formas típicas de mobilização utilizadas até então. No Nordeste Mineiro, nesse período, foram realizadas algumas das primeiras ocupações de terra massivas na forma acampamento (Sigaud, 2000) em Minas Gerais, o que transformou significativamente a luta pela terra na região, seus principais atores e estratégias, com proeminência das ações do Movimento dos Trabalhadores Rurais Sem-Terra (MST). Nesse contexto, as ocupações de terra e formação de acampamentos adquiriram significado central na criação de canais de interação entre sociedade civil e política institucional, em torno da bandeira de luta pela reforma agrária.

No que se refere à construção da pesquisa aqui apresentada, foram realizadas entrevistas junto a alguns dos principais atores na luta pla terra das décadas de 1980 e 1990, assim como analisado material escrito produzido por várias das organizações nas quais atuaram.

Realizamos trinta e quatro entrevistas junto a militantes dos diversos grupos envolvidos nesse processo, como MST, Comissão Pastoral da Terra (CPT), Federação dos Trabalhadores na Agricultura do Estado de Minas Gerais (FETAEMG), Central Única dos Trabalhadores (CUT), sindicatos, etc., assim como integrantes dos vários assentamentos criados nesse processo de luta. Essas entrevistas, assim como sua 
análise, foram pautadas nos referenciais da metodologia da História Oral (Amado e Ferreira, 2002), tanto na modalidade da história de vida quanto questões de ordem temática (Meihy, 1998), procurando, assim, relacionar as trajetórias individuais com suas inserções nos grupos sociais, dinâmicas de relações e representações sobre o processo em questão nessa pesquisa.

A opção pela fonte oral permitiu trazer à tona uma gama de elementos fundamentais para o estudo, pois ela estimula, de forma intensa, referências subjetivas relevantes para que se entendam as visões de mundo em relação nos diversos contextos. Esse potencial fica mais evidente quando se percebe que a História Oral visualiza bem as articulações políticas - as tensões, dúvidas e estratégias - elementos fortemente ligados à memória e à identidade (Halbwachs, 1990; Pollak, 1992). A História Oral contribuiu para captar os silêncios, as memórias ocultas e as subalternidades, articulados dinamicamente e com lógica própria. Enquanto muitos consideraram que os 'silêncios' não podem ser compreendidos pelo trabalho de pesquisa, Portelli (2002), valendo-se da História Oral, considera que não se deve desistir, pois o 'indizivel é dito'. Nesse sentido, ele sugere o procedimento de se relacionar os fatos e constituições narrativas com as articulações específicas da forma de lembrar em cada grupo.

Também foram analisados jornais, cartilhas, panfletos, documentos oficiais, relatórios etc. produzidos por vários organizações nas quais esses militantes atuaram, fontes que - ao serem relacionadas com as entrevistas -trouxeram informações relevantes.

Outro parâmetro para nossa metodologia foram as ferramentas da Micro-história (Levi, 1992; Ginsburg, 1989; Revel, 2000). Essa abordagem pretende -através da redução da escala de observação, da análise densa das fontes e da investigação indutiva- demonstrar as especificidades de seus objetos e o valor dessas especificidades para uma compreensão mais ampla. Sendo assim, o foco se direciona para casos concretos, processos vividos ao rés do chão (Revel, 2000), e para a abertura frente categorias imprevistas, muitas vezes construídas pelos próprios atores sociais. 
Com base nesses parâmetros, foi possivel reconstruir a história de parte significativa desse processo, sobre o qual contamos com pouquíssimos estudos, e desvendar parte das tramas que configuraram a luta pela terra nesse contexto.

\section{Contexto das mobilizações}

Apesar de conflitos de caráter isolado, apenas a partir da década de 1950 a luta pela terra no Brasil adquire maior unidade e visibilidade, em torno da bandeira da reforma agrária. O Partido Comunista Brasileiro (PCB), as Ligas Camponesas e alguns setores da Igreja Católica foram atores fundamentais nesse processo. Cada qual, à sua maneira, desenvolveu estratégias de mobilização visando o redimensionamento da estrutura fundiária e das condições de vida no campo, disputando a organização das classes populares e o processo de sindicalização. Nesse processo, destaca-se a constituição da identidade de camponês, conferindo unidade e abrangência política para as mobilizações dos trabalhadores rurais, em oposição aos latifundiários. (Novaes, 1997).

Após 1964 essas forças foram fortemente combatidas pelo Estado brasileiro que, em muitas situações, inclusive criou condições para aumentar a concentração fundiária. Apesar do surgimento de novas estratégias de luta durante o regime militar, esse foi um período de dispersão e atomização das lutas no campo. Essas ações passaram a ocorrer de forma mais isolada, com poucas e incipientes mediações. O final dos anos de 1960 e os anos de 1970 foram marcadas pela forte repressão política, diante da qual vários grupos buscaram resistir, muitos deles agindo na clandestinidade, sendo duramente perseguidos. Apesar dessas iniciativas -que mantiveram viva a chama da luta pela terra e colocavam em questão a falsa imagem de consenso e harmonia propagada pelo regime civil-militar -essas mobilizações obtiveram pouco sucesso em termos de conquista de terras pelos trabalhadores rurais.

A partir do final dos anos de 1970 e início de 1980 houve um fortalecimento da luta pela terra no Brasil, em convergência com o processo de 
redemocratização política do País, no qual surgiram novos atores, novas demandas e novas formas de enfrentamento (Martins, 2004). Ocorreram transformações importantes nas ações de luta pela terra nesse contexto, especialmente no que se refere a generalização e massificação das ocupações, em grande medida decorrentes da criação $\mathrm{MST}^{4}$ no sul do Brasil e a migração de parte de sus militantes para outras regiões (Lerrer, 2008).

A forma acampamento (Sigaud, 2005) apresentou-se como inflexão nos processos de luta pela terra, ou seja, uma forma de enfrentamento que fortaleceu as possibilidades de interação com o poder público, redimensionou práticas de vários movimentos e organizações no meio rural, relacionando-se com o surgimento de novas identidades políticas. Como afirma Sigaud (2005), "ocupar terras e nelas montar acampamentos tornou-se, nos últimos vinte anos, a forma apropriada para reivindicar a reforma agrária no Brasil" (p. 255). Assim, salienta-se que a forma acampamento é "uma linguagem, um modo de fazer afirmações por meio de atos, destinada a fundar pretensões à legitimidade" (Sigaud, Rosa, e Macedo, 2008).

Essas novas forças ganharam maior relevo em Minas Gerais na segunda metade da década de 1980, quando a organização para a realização das ocupações de terra se tornou mais concreta, principalmente pela ação conjunta entre militantes sulistas do MST, lideres sindicais e membros da Comissão Pastoral da Terra (CPT). Em fevereiro de 1988 foi realizada a primeira ocupação de terra com proeminência do MST em Minas Gerais, no município de Novo Cruzeiro (Vale do Jequitinhonha), com a participação de cerca de 400 famílias da região, dando origem ao Assentamento Aruega. Em seguida foram realizadas outras ocupações -nas fazendas Sapezinho (Novo Cruzeiro, 1988), Bela Vista (Teófilo Otoni, 1989), Limeira-Califórnia (Tumiritinga, 1993) e do Ministério (Governador Valadares, 1994)- muitas delas engrossadas pelos excedentes da primeira ocupação, que teve um caráter emblemático tanto pelo número de trabalhadores rurais mobilizados quanto pela participação de várias organizações.

4 Apesar do MST ter sido oficialmente fundado em 1984, seu surgimento remonta às primeiras ocupações de terra organizadas a partir de 1979 no Sul do Brasil, com apoio da Comissão Pastoral da Terra (CPT). 
Os trabalhadores rurais mobilizados nesse processo são provenientes de pequenas comunidades rurais de vários municípios do Nordeste Mineiro. Em sua maioria, eram agregados, meeiros, posseiros, assalariados e proprietários de terras pequenas, isoladas e desgastadas, insuficientes diante do crescimento da família. Trabalhavam principalmente na agricultura de arroz, feijão, mandioca, milho, café e cana, produtos voltados principalmente para subsistência, tendo pouco excedente para ser vendido nos mercados locais.

O universo cultural dos trabalhadores rurais do Nordeste de Minas Gerais foi historicamente marcado pelo saudosismo em relação aos antigos vínculos entre grupos de posseiros, agregados e fazendeiros, fortemente baseados em relações de reciprocidade, mando, obediência e proteção (Ribeiro, 1996). Essas relações, diluídas no processo de modernização, continuaram como pontos de referência fundamentais para a atuação desses trabalhadores, suas expectativas e escolhas.

Os vínculos e direitos tradicionais de agregados e posseiros perderam seu valor diante das novas forças econômicas, desamparando esses trabalhadores e lançando-os num mundo cujos significados não faziam sentido. Assim, havia uma memória do enraizamento em face da diluição dessas relações, levando essas pessoas ao desejo pelo restabelecimento de uma comunidade rural frente à solidão da sociedade moderna (Ribeiro, 1996).

As relações entre essas famílias mobilizadas e os fazendeiros da região já estavam diluídas, algumas vezes em razão dos latifúndios terem sido vendidos para outros donos, outras pelos antigos fazendeiros terem modificado suas relações com os trabalhadores rurais, principalmente buscando sua proletarização.

Diante desse sentimento de desamparo, muitos trabalhadores vinham buscando enraizamento através da organização de suas comunidades em torno de sindicatos e paróquias. Geralmente eram católicos, muito participantes na vida religiosa de suas comunidades, alguns se tornando lideranças locais das Comunidades Eclesiais de Base (CEBs), que atuavam fortemente na região. O acesso à terra 
através das ocupações surgiu como uma nova possibilidade de enraizamento para esses trabalhadores, uma possibilidade de autonomia e restabelecimento de laços de solidariedade.

\section{Traduções e bricolagens no processo de mobilização}

As ações de mediação consistem na construção de novos arranjos a partir dos fragmentos de significados, disponiveis nos vários universos de significação em relação (Neves, 2008). Essas ações possibilitam a comunicação e ação conjunta entre grupos em interação nos processos sociais, o que assemelha a mediação com as atuações do tradutor e do bricoleur.

Um primeiro ponto que chamou atenção foi a importância dos significados ligados à religiosidade para a comunicação inicial entre trabalhadores rurais e militantes das organizações e movimentos. Isso ficou evidente em depoimentos de atores que buscavam na Bíblia referências para despertar a organização dos trabalhadores na região, desde a década de 1980. Os referenciais bíblicos ficaram evidentes também na cartilha intitulada Terra não se ganha, se conquista: Movimento dos Trabalhadores Rurais Sem Terra, produzida pela CPT de Minas Gerais na década de 1980 -na qual a questão da terra é situada com base em algumas citações:

Deixa tua terra, tua família e a casa do teu pai, e vai para a terra que eu te mostrar - disse Javé a Abraão. Farei de ti uma grande nação; eu te abençoarei, exaltarei o teu nome; e tu, sê uma benção. Abençoarei aqueles que te abençoarem, e amaldiçoarei aqueles que te amaldiçoarem; todas as familias da terra serão benditas em ti. E o Senhor apareceu a Abraão e disse-lhe: Eu darei esta terra aos teus descendentes. (Gênesis 12, 1-3-7)

Clamamos ao senhor, Deus de nossos pais, o qual nos ouviu, olhou para o nosso sofrimento, trabalho e angústia, e nos tirou do Egito com mão forte e braço poderoso, com grande espanto, com 
sinais e prodígio; introduziu-nos neste lugar e deu-nos esta terra que corre leite e mel (Deuteronômio 26, 7-9) (Terra não se ganha, se conquista: Movimento dos Trabalhadores Rurais Sem Terra. p. 26).

As passagens bíblicas valorizavam a ideia de uma travessia, de coragem para deixar os antigos vínculos para trás, em analogia com as ocupações de terra e vida nos acampamentos.

Grande parte dos militantes do MST que atuaram junto aos trabalhadores nas ocupações estavam ligados a grupos organizados por segmentos progressistas da Igreja Católica, como a CPT, e alguns já traziam experiência de atuação religiosa nas comunidades rurais mobilizadas. Paulo explicou como foi sua entrada na militância do MST fortemente influenciada pela atuação de grupos religiosos na região - e argumentou sobre a importância dessa participação para a realização das mobilizações:

De qualquer forma se deu na Igreja mesmo. Naquele período, estava no auge da construção das Comunidades Eclesiais de Base e o grande lema daquela época era a luta pela terra, essa ala mais revolucionária... Então essa turma, esse padre lá da minha paróquia, o Jerônimo, ele era dessa ala da Igreja, a ala mais combativa da Igreja. A preocupação dele era construir as CEBs e a partir dai já com possibilidade de construção de movimentos sociais. Foi realmente um trabalho dificil e o que contribuiu muito foi a aceitação da Igreja, porque o povo é muito religioso, então a coisa poderia parecer dificil, mas se levava a discussão religiosa junto, a partir da fé ai... Assim, como o trabalho de base era muito da Igreja, a gente fazia a discussão voltada para a missão do Messias mesmo, etc. Ai o pessoal quebrava o medo e... enfim, se disponibilizava. (Paulo, entrevista ao autor, 19/03/2011, grifos nossos)

Grande parte dos depoimentos demonstra como as reflexões anteriores, muitas vezes em CEBs, já haviam criado uma perspectiva crítica dos trabalhadores sobre a realidade que vivenciavam e já colocavam a reforma agrária como ideal. Nesse mesmo sentido, a aceitação das novas ideias e ações passou pela tentativa de inserção -da forma mais coesa possível- nessas lógicas anteriores e redes de relações. 
Houve, assim, um esforço de mediação para relacionar as utopias políticas de organizações e movimentos sociais e as representações religiosas de grande parte dos trabalhadores rurais envolvidos, o que contribuiu para a criação de relações de confiança e facilitou a comunicação das novas propostas de ação. As mobilizações iniciadas a partir de meados da década de 1980 foram possiveis, em grande medida, pela existência de trabalhos de base anteriores que já haviam constituído certo sentimento de injustiça e questionamento da realidade agrária local e nacional, com forte fundamento na religiosidade popular. Nessas relações, foram realizadas bricolagens entre significados religiosos e políticos de alguns dos atores envolvidos, como na aproximação entre a representação sobre Jesus Cristo -associada à insubordinação frente às injustiças e relações de opressão- com o questionamento sobre o status quo que movimentos e organizações realizavam na luta pela terra.

Também foi frequente a combinação entre as representações bíblicas sobre a Terra Prometida -conquista marcada por travessias, grandes sacrificios- com a luta pela terra através de ocupações e formação de acampamentos, espaços de desestruturação e, em certa medida, reestruturação do cotidiano social das famílias mobilizadas. Assim, foram possiveis traduções (Santos, 2003) entre as linguagens políticas das organizações envolvidas e a linguagem religiosa de grande parte dos trabalhadores rurais mobilizados, possibilitando comunicação e envolvimento mútuo em torno de ações conjuntas no sentido das ocupações de terra, assim como a projeção dessas mobilizações locais para instâncias mais amplas.

Para Santos (2003), o trabalho de tradução é procedimento que cria inteligibilidade mútua entre experiências, não atribuindo o status de totalidade exclusiva a nenhuma delas, mas sim reconhecendo sua incompletude. Assim, a tradução -ao identificar elementos comuns- permite o encontro entre motivações de diferentes grupos, fortalecendo as possibilidades de agregação sem, com isso, levar à perda de autonomia. Dessa forma, o trabalho de tradução propicia o diálogo e a formação de formas híbridas de conhecimento e atuação social e política, processo que não está livre de tensões diante das várias e, algumas vezes, destoantes linguagens em relação. 
Nesse mesmo processo, algumas ações de mediação aqui discutidas se direcionaram cada vez mais para o questionamento da autoridade e legitimidade do domínio dos fazendeiros sobre a terra, o que contribuiu na formação de uma perspectiva política oposta. Assim, caminhou-se no sentido da delimitação e enfrentamento de adversários no seio da sociedade, direcionando reflexivamente para a compreensão dos latifundiários como adversários dos sem-terra.

No depoimento abaixo, Sebastião -liderança local em Aruega- narrou parte das argumentações utilizadas nos trabalhos de base, demonstrando as inquietudes dos trabalhadores rurais e a necessidade de deslegitimar a figura do fazendeiro, ruptura sem a qual a ocupação da terra não seria percebida como algo legítimo:

Eles (lideranças) falavam: "A gente num vai ocupar uma terra que tem dono. Vamos ocupar uma terra improdutiva”. Ai quando as pessoas falavam: "Isaias, num tem jeito Isaias, como é que nós vamos tomar a terra do outro?". Ele respondia: "Não gente, a terra que o Movimento ocupa é terra que o dono não paga imposto. A maior parte dela não tem documento." Ai tentava convencer que a situação é essa, que Aruega é 966 hectares de terra, mas o dono tem documento de 246. Cadê as outras? As outras era dele? Não era! [...] A dele ninguém tomou, ta ai. Ele num tá trabalhando nela porque? Por que ele não trabalha! (Sebastião, entrevista ao autor, 13/07/2005, grifos nossos)

Enfatizavam que as terras eram objeto de grilagem, devolutas ou não estavam sendo usadas para produção pelos latifundiários. Esses argumentos eram reproduzidos pelas lideranças locais, que foram assumindo cada vez mais a forma de um discurso de enfrentamento, buscando romper com as tradicionais relações de obediência e proteção que marcavam as lembranças dos antigos agregados da região. Vários depoimentos demonstram que, nesse processo de mediação, se articulou um pensamento de que o vínculo com a terra é de quem nela trabalha e não de quem a expropriou e explorou enquanto mercadoria, num processo de reenquadramento das concepções sobre direitos. A busca pela contraposição entre trabalhadores e fazendeiros é evidente, sendo o sofrimento de uns situado como consequência da exploração 
do outro, de um privilégio que trazia consequências perversas, ou seja, o sofrimento dos trabalhadores e latifúndio são pensados como faces de uma mesma moeda. Ao salientarem que o fazendeiro não trabalha, caminhou-se no sentido da constituição de uma bricolagem entre as representações sobre a importância do trabalho na terra -um valor para os trabalhadores rurais- e a ideia de 'função social da terra'5 presente nas concepções políticas dos movimentos e organizações sociais envolvidas nesse processo, sendo uma das bandeiras históricas na luta pela terra no Brasil. Assim, a valorização do trabalho na terra e a ideia de 'função social da terra' foram combinadas num arranjo que permitiu a constituição de uma imagem negativa do latifundiário e, assim, contribuiu para a legitimação das ocupações.

Mais um ponto também relevante para as ações de mediação foi a busca pela formação de um sentimento de que, ao se unirem e se organizarem, os trabalhadores teriam a força de modificar as relações de poder estabelecidas. O incentivo para esse sentimento de força pela união está presente em várias situações, inclusive no material impresso distribuído pelos militantes dos grupos mobilizados. Além dos textos que trazem fortemente essa ideia, imagens buscam ilustrar esse sentimento que visavam fortalecer:

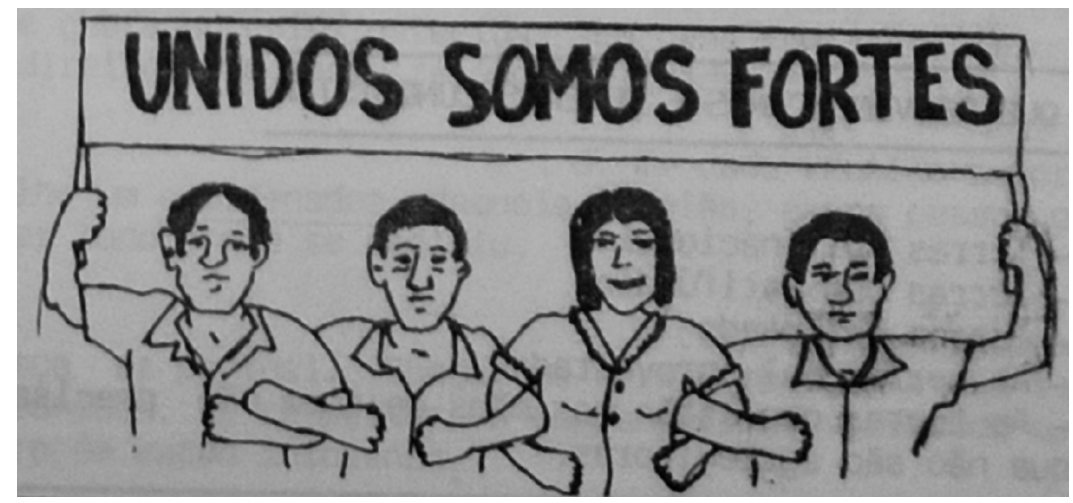

Figura 1: Unidos somos fortes

Fuente: Caderno de formação do MST, no 1 (1986). p. 7.

'Função social da terra' é um termo legal, introduzido no Estatuto da Terra (1964), que foi recorrentemente utilizado na luta política. 
Referindo-se à ocupação de Aruega, tida pelos vários atores como vitoriosa, alguns entrevistados ressaltam como superaram o temor atribuído à herança coronelista da região, dando indícios sobre a existência crescente desse sentimento de força coletiva nas mobilizações:

Municípios que tinham herança mais... mais assim forte do coronelismo, pegando ali para aquelas bandas de Novo Cruzeiro mesmo, Padre Paraíso, Águas Formosas, alguns só sabe falar do tal de Juca Quaresma, grande capitão ali daquela região. Então o pessoal tinha muito medo mesmo. Aí nós tivemos que esclarecer pra eles, até trazer fotos, alguns slides em relação à luta que estava acontecendo no sul, no Espírito Santo, na Bahia. A gente mostrando pra eles como a força do povo rompia a repressão dos fazendeiros e tal e mostrando fotos bonitas, aquela imensidão de gente cortando arame, quebrando porteira... (Paulo, entrevista ao autor, 19/03/2011, grifos nossos)

Havia, assim, grande resistência dos trabalhadores rurais de várias comunidades em entrar nessas mobilizações, que se pautavam no enfrentamento contra poderes temidos, respeitados e, muitas vezes, que gozavam de grande legitimidade para esses trabalhadores. O esforço nesse momento foi para desconstruir os fragmentos das antigas relações de obediência e proteção tradicionais, demonstrando que eram possiveis outras forças, ligadas à união dos mais fracos.

Vários depoimentos indicam como grande parte do trabalho de base girou em torno de demonstrar a força que os movimentos vinham adquirindo frente a poderes antes considerados inquestionáveis e inatingiveis, em convergência com o processo de redemocratização política em várias regiões do Brasil. Esse esforço foi para quebrar o medo frente ao autoritarismo e a violência fortemente presentes nos discursos dos fazendeiros e autoridades da região. Diante do recente e incipiente processo de redemocratização no Brasil, a rearticulação de formas de autoritarismo eram estratégias recorrentes dos grupos que buscavam desarticular os processos de ocupações, espalhando o temor em relação à violência e impunidade típica do regime civil-militar (1964-1985). 
Contra esses obstáculos, os militantes dos grupos mobilizados buscavam demonstrar a existência de outra forma de poder, relacionada à conquista de direitos pela e para a coletividade. Estava em curso uma busca pelos sentimentos de autoestima e autoconfiança (Honneth, 2003), que foram relacionados com a construção do reconhecimento de uma força coletiva que pudesse contrabalançar as relações de poder vigentes.

Num dos depoimentos, Paulo atribui a esse sentimento de força coletiva, que vinham construindo nas ações de mediação, um status de 'mito', que fez com que as pessoas assumissem posturas de enfrentamento com base na crença numa grande força coletiva que, se não fosse pela própria crença, não existiria. Essa suposta força, segundo depoimentos, gerou união no grupo e temor nos adversários:

Nós conseguimos por diversas vezes correr com a polícia. Enfim, e nós criamos um... um mito ali de resistência, que muitas vezes chegava a ser mito mesmo. Nós não tínhamos a... a força real que aparentemente parecia ter. Mas, assim, criamos um certo pavor mesmo. [...] Nós, na ocupação de Aruega, conseguimos isso. Fruto... não é mérito só da liderança, mas do Movimento naquele conjuntura. (Paulo, entrevista ao autor, 19/03/2011)

Assim, a ação conjunta -com sua força motivada por esse mitoacabou por concretizá-lo, numa profecia que se realizou, um círculo virtuoso que motivou os trabalhadores a continuarem empenhados na luta e a expandirem com maior confiança.

O processo de construção do sentimento de força coletiva está também associado à ideia de que não se lutava pontualmente apenas por aquelas terras, mas também por uma causa, pela construção de uma nova sociedade, uma utopia, elemento fundamental na dinâmica dos movimentos sociais (Neveu, 2005). Dessa forma, os anseios pela terra dos trabalhadores rurais mobilizados -conquista fundamental para seu enraizamento- foram articulados com a bandeira mais ampla pela reforma agrária, acrescentando um maior sentimento de legitimidade 
para suas ações ao estarem envolvidos num processo que possibilitaria uma conquista para a sociedade como um todo.

Outro fundamento desse sentimento de força descrito anteriormente está na busca pela criação de uma consciência sobre a interdependência entre as mobilizações que se constituiam localmente, as organizações e movimentos sociais e o poder do Estado. Assim, a criação, no trabalho de mediação, de relações com as instituições políticas -mostrando que esse conflito era também um problema a ser resolvido pelo poder público, que estaria acima do jogo de interesses locais- trazia o sentimento de que o processo em curso transcendia os limites do acampamento, o que encorajava os trabalhadores rurais mobilizados.

Como salientado por Medeiros e Esterci (1994), as mediações levam movimentos e grupos a transcenderem sua dimensão local e particular, ligando-os a outros grupos e instâncias. Dessa forma, as mobilizações ganharam significado e força diante da interação entre atores de vários contextos, cuja ligação foi possivel diante de um esforço de aproximação e construção de objetivos em comum.

O depoimento de Estefani -liderança do MST nesse processo- demonstra como havia o direcionamento das mobilizações para a esfera institucional, as 'autoridades', que teriam que se posicionar diante desse conflito. Assim, mesmo sabendo das limitações em termos de quantidade de possiveis beneficiários pelo assentamento, as ações eram pensadas como mecanismo de intervenção na esfera política, o que poderia trazer consequências mais amplas:

A gente queria melhorar [...] pelo menos mostrar para a sociedade. Porque a gente sabe que um acampamento daquele não ia melhorar a nivel da quantidade de pessoas que existiam na época sem terra, sem comida, porque o povo era sem comida mesmo! A gente sabia que isso não ia resolver, mas pelo menos para chamar atenção das autoridades, mostrar para a sociedade que tinha como melhorar, mas que as autoridades da época não queriam uma melhora, parecem que não tinham sentimento de ver as pessoas sofrendo, passando por dificuldade. (Estefani, entrevista ao autor, 22/10/2012, grifos nossos) 
Em vários depoimentos se revela como políticos influentes -como, por exemplo, deputados estaduais e federais- estavam mobilizados em torno dos desdobramentos das ocupações em curso. Os enfrentamentos locais, desencadeados no contexto de redemocratização do país, estavam intimamente relacionadas com os embates em outras instâncias, no Executivo, Legislativo e Judiciário. As pessoas mobilizadas no acampamento acompanhavam as batalhas nessas outras instâncias, percebendo suas relações e se sentindo como parte de um processo de luta mais amplo, o que lhes trazia mais confiança.

Em depoimentos e conversas informais foram ressaltados: o apoio de deputados, bispos e organizações; as articulações em torno da emissão e derrubada de liminares de despejo e o uso estratégico da opinião pública -informações que indicaram que estava em curso a construção de redes entre grupos mobilizados na sociedade civil, opinião pública e política institucional. Dessa forma, foram realizadas traduções que permitiram relacionar as mobilizações nos acampamentos com a atuação de agentes noutras instâncias. Assim, sob a bandeira mais ampla da luta pela reforma agrária, uma variedade de ações ganhou maior unidade e legitimidade. Nessas traduções, foram propiciadas comunicações entre os referenciais políticos e culturais dos diversos grupos envolvidos, como as concepções religiosas e desejo pelo enraizamento dos trabalhadores rurais, ideais de transformação social das organizações e movimentos sociais, e as bandeiras politicas mais amplas levadas ao âmbito institucional por membros do Estado, como funcionários do Instituto Nacional de Colonização e Reforma Agrária (INCRA) e deputados estaduais e federais.

$\mathrm{Na}$ construção de uma linguagem em comum, que congregava as concepções e ações desses diversos atores, foi possivel situar as ocupações de terra como estratégia amplamente aceita e incentivada, mesmo que o ponto de partida fossem os diferentes significados atribuídos a essa estratégia pelos diversos atores em relação: acesso a um pedaço terra, luta pela reforma agrária, luta por uma nova sociedade, construção de politicas públicas voltadas para os trabalhadores rurais etc. 


\section{Descompassos e reações}

Apesar de uma análise panorâmica das mobilizações do MST nas décadas de 1980 e 1990 indicar como esse movimento foi paulatinamente ganhando força, nossas análises mais pontuais demonstram que esse processo não se deu de forma linear. As ocupações realizadas entre 1988 e 1997 foram marcadas também por momentos de enfraquecimento frente às discordâncias entre os aliados e reações dos adversários (fazendeiros, políticos locais, forças policiais etc.), atingindo o cerne das ações de mediação que vinham sendo construídas.

Integrantes do MST e da CPT, principais organizações à frente dessas mobilizações, tiveram fortes divergências relacionadas às diferentes perspectivas sobre o grau de confrontação que se deveria ter frente aos adversários. Alguns depoimentos apontam que o MST pressionou no sentido de um enfrentamento mais intenso -como resistência aos despejos, ocupação de terras ainda não desapropriadas- e a CPT optou por uma postura mais voltada para a negociação, posições divergentes que enfraqueceram suas ações conjuntas.

Essas tensões ficaram evidentes quando várias lideranças compararam a ocupação de Aruega -onde CPT e MST ainda estavam mais unidos e a terra foi conquistada- com algumas das ocupações subsequentes, que foram despejadas, não conseguindo a terra:

Tem momentos que a liderança opta por um caminho muito de aliança, de negociações, que não surte efeito. E há momento em que as pessoas tomam uma decisão um pouco mais radical, de combate mesmo e acaba sendo vitorioso. Quando nós ocupamos Aruega nós não tínhamos nenhuma pretensão de negociar. Negociar em que sentido? Ah, do proprietário chegar, com aquela conversinha doce e tal... Quer dizer, entramos com um propósito muito claro de radicalização mesmo! Radicalizamos o máximo! Tanto é que a polícia não conseguiu entrar. (...) Quando ocupamos Sapezinho, que é a Fazenda ao lado, era basicamente o mesmo grupo de liderança. Por influência inclusive até da própria CPT... os aliados... flexibilizou. (Paulo, entrevista ao autor, 19/03/2011, grifos nossos) 
Estava em disputa, principalmente, a forma e a intensidade do enfrentamento que os trabalhadores rurais teriam frente às tentativas de despejo e realização de novas ocupações. Enquanto grande parte dos militantes do MST via aquele momento como decisivo para a continuidade do processo de ocupações, membros da CPT acreditavam ser melhor recuar, ter uma postura mais moderada, em vista do risco dos trabalhadores rurais serem despejados violentamente.

Essas divisões possibilitaram também que os atores contrários as mobilizações pudessem articular significados no sentido da manutenção das relações de poder. Como salientado por Novaes (1994) é necessário pensar a mediação para além dos atores comprometidos com os interesses dos trabalhadores, ou seja, é pertinente pensar também as formas de mediação a serviço da manutenção das relações de poder. Nas entrevistas, um dos principais motivos alegados para o 'fracasso' da ocupação de Sapezinho foi o consentimento da frequente entrada da dona da fazenda e da polícia no acampamento, supostamente visando o diálogo e a doação de alimentos, remédios etc. enviados por ela para os sem-terra. Isso teria amainado a oposição dos trabalhadores dada a habilidade de convencimento e formação de uma boa autoimagem pela dona da fazenda. Assim, argumentam que a mobilização foi enfraquecida, o que teria facilitado a inserção da polícia, descoberta de informações estratégicas e a retirada dos trabalhadores rurais da terra.

Aceitamos inclusive sentar na mesa de negociação com a proprietária, e a proprietária teve uma habilidade tamanha de nos enrolar, mas enrolou bacana! A ponto de um dia a reunião se dar na fazenda dela. Um dos equívocos mais vergonhosos de se contar que nós cometemos, nós caímos no conto de fadas. Acreditamos que aquela negociação que tinha se estabelecido ai nós íamos conquistar a Fazenda. Negociação com político, com a proprietária, com o INCRA, não sei o que e tal, e apostamos nisso e flexibilizamos a resistência interna. (...) Era um imbróglio mesmo... Ela conseguiu estrategiar uma metodologia tão eficaz de nos desgraçar. Ela levava leite pras crianças! Fornecia leite, levava. Ela infiltrou no acampamento! Ela e seus... Ai chega a polícia com o mesmo discurso: "Não, que nós estamos pra proteger e tal”. (Paulo, entrevista ao autor, 19/03/2011, grifos nossos) 
Paulo é enfático ao afirmar que a perspectiva que vinham construindo, oposta à figura do fazendeiro, foi minada nesse processo. A autoridade das lideranças foi abalada diante de forças que passavam a ganhar/retomar legitimidade frente os trabalhadores rurais, como a fazendeira e a polícia militar. Cauã -um trabalhador rural acampado, fortemente ligado à CPT- contou alguns acontecimentos reveladores sobre esse processo:

A polícia acampou no meio de nós e foi cadastrando o pessoal. Dizia: "O governo vai dar uma terra para vocês". Essa era a promessa da polícia! Aí o MST viu que eles tomavam o povo mesmo, ia desbaratar o acampamento ali. [...] O Movimento perdia o povo, as lideranças tinham que ficar quieto, não podia fazer uma reunião, porque eles queriam pegar as lideranças. (Cauã, entrevista ao autor, $25 / 10 / 2012$, grifos nossos)

O fato dos policiais militares optarem por acampar junto aos trabalhadores rurais - distribuindo alimentos, realizando cadastros e prometendo que seriam assentados noutro lugar - é muito significativo, pois indica a busca por uma convivência que permitisse, além de controle físico, ações de mediação sobre os acampados que pudessem desmotivá-los ao enfrentamento. Nesses momentos de convivência, os policiais tentavam minar a credibilidade do MST junto aos acampados, restabelecer a confiança na ordem vigente, nos valores tradicionais de respeito em relação às autoridades e hierarquias constituídas. Assim, as significações sobre certos valores dos atores em conflito estavam em disputa intensa, sendo elementos centrais na definição dos rumos desse processo.

Nesse contexto, também a proprietária da terra buscou evitar que os militantes mediassem a construção de sua imagem como adversária para os trabalhadores rurais. Em vários depoimentos de assentados ficou claro como a figura do fazendeiro, geralmente uma imagem abstrata para os trabalhadores, ganhou concretude a partir da presença frequente da dona da terra no acampamento, suas doações, promessas e demonstrações de sofrimento: 
Naquela época o fazendeiro quase não aparecia. Eu conhecia a dona da Fazenda Sapezinho, vi por umas três vezes. Sempre ela chegava chorando: "Que eu vou vender essa terra para o Governo, pra vocês assentar e tal". Trazia leite para as criancinhas, mas aquilo era só para engañar. (Policarpo, entrevista ao autor, julio 7, 2013)

Nessa situação de aproximação com os sem-terra e imagem de sofrimento, ao que tudo indica, a fazendeira e a policia conseguiram valer-se das memórias sobre as relações de mando/obediência e proteção -típicas das antigas relações de agrego na região- para enfraquecer a oposição dos trabalhadores rurais e de parte das suas lideranças.

O sentimento de força pela união, fundamental para as mobilizações, também sofreu forte impacto diante dos despejos realizados, tanto nos mais violentos, como no da Fazenda Bela Vista em 1989, quanto nos mais simbólicos, como no da Fazenda do Ministério em 1993. Nesse último, destaca-se a presença de um aparato policial desproporcional e da banda de música da Polícia Militar durante o despejo, numa clara tentativa de humilhar os trabalhadores rurais e abater sua autoconfiança.

Essas ações conservadoras -assim como a inexistência de regulamentação sobre as desapropriações ${ }^{6}$ - fez com que as mobilizações fossem retraídas entre os anos de 1989 e 1993. No entanto, após esse período, o movimento retoma seu crescimento, rearticulando as ações de mediação abaladas, direcionando suas iniciativas para o Vale do Rio Doce.

O caso da Fazenda do Ministério é emblemático para essa retomada. Essa fazenda, almejada pelos trabalhadores rurais mobilizados na década de 1960, foi um dos pivôs do golpe civil-militar de 1964, se tornando um símbolo da força política dos fazendeiros da região ${ }^{7}$. No

6 A Constituição de 1988 previa a desapropriação pela função social e improdutividade da terra, no entanto os dispositivos constitucionais para sua realização somente foram regulamentados em 1993.

7 A Fazenda do Ministério foi ocupada pelos trabalhadores rurais mobilizados pela reforma agrária no início da década de 1960, gerando grande tensão e conflitos entre proprietários rurais, lideres sindicais, trabalhadores rurais, politicos etc. A notícia de que a Fazenda seria destinada aos trabalhadores pelo Governo Goulart se espalhou, sendo um dos estopins para a reação conservadora que culminou no golpe civil-militar de 1964. 
início da década de 1990, as mobilizações do MST tornaram essa terra novamente objeto de luta, transformando seu significado.

A Fazenda do Ministério, através das ações de mediação, passou a indicar a retomada do antigo conflito. Assim, cada vez mais, essa área passou a significar o direito dos trabalhadores rurais solapado por décadas, objeto de sua luta, uma área que estava destinada para reforma agrária e que, assim, deveria ser ocupada para o fechamento desse ciclo. Assim, buscou-se colocar a Fazenda do Ministério como símbolo de uma batalha perdida, noutro momento, mas que esse quadro poderia ser modificado pela união dos trabalhadores rurais num novo contexto, numa correlação de forças diferente, na qual os trabalhadores rurais mobilizados teriam sucesso.

Dessa forma, ao rearticular seu olhar para os antigos conflitos na fazenda, esses atores reavaliaram suas memórias, conferindo-as novos significados, de acordo com o contexto de mobilização que estavam vivenciando, aumentando suas possibilidades de transformação da realidade em que viviam. Depois de um intenso processo de luta, essa terra foi conquistada em 1997, assim como outras fazendas da região, indicando uma nova ascensão das mobilizações.

\section{Considerações finais}

A pesquisa aqui apresentada buscou demonstrar que as ações de mediação se deram no sentido da constituição de bricolagens entre elementos dos universos de significação -religiosos, políticos, culturais etc.- dos vários grupos envolvidos, caminhando na direção da formação de certas significações, que unificaram esforços dos trabalhadores rurais mobilizados em direção a um sentimento de força coletiva e à delimitação de certos atores como adversários (fazendeiros, policiais, poderes locais etc.), possibilitando, assim, a realização das referidas ocupações de terra e o consequente assentamento de parte das famílias mobilizadas. 
No entanto -dada a multiplicidade de atores que influíram nesse processo, com diferentes perspectivas e estratégias- essas mediações também foram marcadas por descompassos, tensões e disputas entre os principais movimentos e organizações que pretenderam mobilizar os trabalhadores rurais. Assim, existiram momentos de enfraquecimento das ações conjuntas, que, em certos casos, dificultaram a resistência nos acampamentos, permitindo a realização de despejos.

Os adversários também influíram nesse processo, buscando desarticular as mobilizações, no sentido da manutenção das relações de poder. Assim, fazendeiros, policiais, prefeitos etc. também realizaram mediações, rearticulando valores tradicionais -relacionados às antigas relações de mando/obediência/proteção- minando, em parte, a legitimidade das lideranças dos movimentos e enfraquecendo as significações em construção.

Assim, tratou-se de um processo dinâmico -com diferentes configurações de poder ao longo de cerca de dez anos de mobilização- e relacional, em vista da interação entre vários atores que interviram nesse processo, com suas diferentes expectativas e estratégias.

\section{Referências}

Amado, J. e Ferreira, M. M. (Orgs.) (2002). Usos e Abusos da História Oral. Rio de Janeiro: Fundação Getúlio Vargas.

Ginzburg, C. (1989). Sinais: raízes de um paradigma indiciário. Em Mitos, emblemas, sinais (pp.143-179). São Paulo: Cia das Letras.

Halbwachs, M. (1990). A memória coletiva. São Paulo: Vértice.

Honneth, A. (2003). Luta por reconhecimento: a gramática moral dos conflitos sociais. São Paulo: Editora 34. 
Lerrer, D. F. (2008). Trajetórias de Militantes Sulistas: nacionalização e modernidade do MST. (Tese Doutorado de Ciências Sociais em Desenvolvimento, Agricultura e Sociedade) Rio de Janeiro: CPDA/UFRRJ.

Levi, G. (1992). Sobre a micro-história. Em Burke, P. (Org.). A escrita da história: novas perspectivas (pp. 133-161). São Paulo: Unesp.

Martins, J. S. (2004). Reforma Agrária: o impossivel diálogo. São Paulo: Ed. USP.

Medeiros, L. S. de e Esterci, N. (1994). Introdução. Em Medeiros, L. (Org.). Assentamentos Rurais: uma visão multidisciplinar. São Paulo: Ed. Da Universidade Estadual Paulista.

Meihy, J. C. (1998). Manual de História Oral. São Paulo: Edições Loyola.

Neves, D. P. (Org.) (2008). Desenvolvimento social e mediadores politicos. Porto Alegre: Ed. UFRGS.

Neveu, É. (2005). Sociologie des mouvements sociaux. Paris: Le Découverte.

Novaes, R. R. (1994). A mediação no campo: entre a polissemia e a banalização. Em Medeiros, L. (Org.). Assentamentos Rurais: uma visão multidisciplinar. São Paulo: Ed. Da Universidade Estadual Paulista.

Novaes, R. R. (1997). De corpo e alma: catolicismo, classes sociais e conflitos no campo. Rio de Janeiro: Graphia.

Pollak, M. (1992). Memória e identidade social. Estudos Históricos, 5(10), 200212.

Portelli, A. (2002). O massacre de Civitella Val di Chiana [Toscana: 29 de julho de 1944]: mito, política, luta e senso comum. Em Amado, J., e Ferreira, M. (Orgs.). Usos e Abusos da História Oral. Rio de Janeiro: Fundação Getúlio Vargas.

Revel, J. P. (2000). Em Levi, G. A Herança Imaterial: trajetória de um exorcista no Piemnote do século XVII. RJ: Civilização Brasileira. 
Ribeiro, E. M. (Org.) (1996). Lembranças da terra: histórias do Mucuri e Jequitinhonha. Contagem: CEDEFS.

Santos, B. S. (2003). Para uma sociologia das ausências e uma sociologia das emergências. Em Santos, B. S. (Org.). Conhecimento prudente para uma vida decente: "Um discurso sobre as ciências" revisitado. Porto: Afrontamento.

Sigaud, L. (2000). A Forma Acampamento: Notas a Partir da Versão Pernambucana. Novos Estudos Cebrap, 58, 73-92.

Sigaud, L. (2005). As condições de possibilidade das ocupações de terra. Tempo Social, 17(1), 255-280.

Sigaud, L., Rosa, M. y Macedo, M. E. (2008). Ocupações de Terra, Acampamentos e Demandas ao Estado: Uma Análise em Perspectiva Comparada. DADOS Revista de Ciências Sociais, 51(1), 107-142.

Zangelmi, A. J. (2014). Traduções e Bricolagens: mediações em ocupações de terra no Nordeste Mineiro nas décadas de 1980 e 1990 (Tese Doutorado de Ciências Sociais em Desenvolvimento, Agricultura e Sociedade). Instituto de Ciências Humanas e Sociais/Universidade Federal Rural do Rio de Janeiro.

\section{Cómo citar este artículo}

Zangelmi, A. J. (2016). Traduções e bricolagens: mediações em ocupações de terra no Nordeste de Minas Gerais (Brasil) nas décadas de 1980 e 1990. Universitas Humanística, 81, 179-203. http:/ /dx.doi.org/10.11144/Javeriana. uh81.tebm 